\title{
Research on China's PPP Financial Affordability Evaluation
}

\author{
Zhao Yu ${ }^{1}$, Cao Fuguo ${ }^{2}$ \\ ${ }^{1}$ School of Public Finance and Tax, Central University of Finance and Economics, Beijing, China \\ ${ }^{2}$ School of Law, Central University of Finance and Economics, Beijing, China
}

Email address:

zhaooooyu@163.com(Zhao Yu)

\section{To cite this article:}

Zhao Yu, Cao Fuguo. Research on China's PPP Financial Affordability Evaluation. Journal of World Economic Research. Vol. 7, No. 2, 2018, pp. 64-72. doi: 10.11648/j.jwer.20180702.13

Received: May 7, 2018; Accepted: June 4, 2018; Published: June 15, 2018

\begin{abstract}
This paper studies the reasons that PPP may cause fiscal risk in provision of public services, and points out the necessity of expenditure-scale control in the application of PPP and the essence of financial affordability evaluation. Through analysis on the shortcomings in the current PPP financial affordability evaluation, it puts forward some issues such as the low reliability of China's financial affordability evaluation, lack of supervision on non-general public budgets and backward government accounting system. In addition, this paper proposals policy suggestions of enhancing the provincial-level financial department in the function at management and supervision in accordance with specific issues; of standardizing the government expenditure management; of fully establishing a comprehensive financial reporting system of accrual accounting system by government; and of advancing the legislative process, with a view to provision of reference for China's PPP fiscal risk management.
\end{abstract}

Keywords: PPP, Financial Affordability Evaluation, Risk Management

\section{Introduction}

As the economic development of China into the "new normal", the conflict between revenue and expenditure of the local governments have been in increasingly prominent. Even more serious is that the local-government debt risk is continuously accumulating and the debt rate of some local governments with backward economic development even exceeds $100 \%$. The contradiction between revenues and expenditures is being increasingly intensified, the sustainability of local finance is facing greater challenges, while the gap of public goods and services supply is expanding. How to improve the quantity and quality of public goods and achieve an equalization in public services under limited financial resources has become a problem that local governments need to solve urgently. A breakthrough in the reform has been shaped by constantly opening up the construction and operation of public products to private capital, relieving the pressure on fiscal expenditure, and improving the level of public service construction and sharing. Serving as a strategy of modernized governance and a tool of importance to the reform of the administrative system, fiscal system and investment and financing system, the Public
Private Partnership (abbreviation for PPP) is undoubtedly an effective carrier to optimize the supply of public services, alleviate the local government debt pressure, resolve over-capacity, and promote supply-side structural reform.

PPP is defined as the cooperation between the public and private sectors to provide public goods or services. After nearly four years of development, PPP has achieved remarkable performance. However, it has concurrently exposed the problems such as the backward legal construction, lack of experience and weak awareness of risk. In particular, the prevention and control of fiscal risk has not yet received sufficient attention. Placing hopes on investment boosting economic growth, local governments launched a large number of PPP projects but ignored the financial capacity, leaving hidden dangers of paying default.

"In order to promote the implementation of PPP projects in an orderly way it must ensure that the government fulfill its contractual obligations and prevent fiscal risk effectively," the Guidelines for the Financial Affordability Assessment of PPP (hereinafter referred to as Guidelines) was issued by the Ministry of Finance in April 2015. Since the implementation of the Guidelines, it has been constantly questioned. Some viewpoints argued that the financial affordability evaluation 
has constrained the development of PPP. Through an in-depth study on the financial affordability evaluation, this paper analyzed the necessity and essence of the financial affordability evaluation, and affirms its important role in prevention for the fiscal risk of PPP projects and elimination of the concerns of private sector. Meanwhile, it pointed out the problems in China's financial affordability evaluation, and finally drew a conclusion and put forward effective recommendations.

\section{Literature Review}

M PetriMaskin, Tirole (2008), Corbacho A and Schwartz G (2008) believed that while PPP provided new opportunities for the development of public infrastructure, it also brought huge fiscal risk. B Andersonet et al. (2006) pointed out that PPP can be used to avoid the expenditure control, remove government investment from the budget, and exclude the debt from the balance sheet. M Hammamiet et al. (2006) argued that the government, out of consideration on political rather than public interest, usually tended to retain more risks, provided various guarantees, and taken excessive contingent liabilities. A Wibowoet et al. (2012) believed that the government may face considerable fiscal risk due to the contingent liabilities incurred by the guarantees although the provision of guarantee can be conducive to an improvement in credibility of PPP projects. This required a systematic analysis of contingent liabilities to understand the full extent of its risk. Dailami and Klein (1997) suggested that the government should assess its commitment obligations and annual budgeting arrangements. A Almassi, B McCabe, and M Thompson (2013) believed that if the government incorporated contingent liabilities into the budget, then the important question was whether the budget was sufficient to meet the obligations guaranteed during that budget year. B Akitoby, R Hemming, and G Schwartz (2007) agreed that the use of extra-budgetary funds could break through the budgetary constraints, but it would lead to a higher medium and long-term cost. If the debt sustainability analysis indicated that the proposed PPP project had a significant risk, the government should consider imposing an upper limit on the overall scale of projects and clearly stipulate the future payment obligations of that country in the PPP program.

The department of international finance cooperation of the Ministry of Finance (2014) believed that the application of PPP could reduce public debt and help the improvement of fiscal sustainability. However, the implementation of PPP projects also involved new fiscal risk, including direct debt, contingent liabilities or fiscal capital requirements caused by implicit guarantee. The key for local governments to carry out PPP projects is to identify and manage contingent liabilities. Wen Laicheng et al. (2015) considered that PPP was a public-service-supplying method with high fiscal risk. The lack of legal and moral constraints had increased the financial risk of PPP projects. At present, large-scale advancement of PPP projects across China was prone to financial risk. Ji Fuxing (2015) thought that PPP may induce fiscal illusions and risk concealment. Government various irrational guarantees or commitments, unreasonable subsides or compensation detached off the balance sheet and are not included in the budget and liability management. Thus inevitably, a heavy financial burden in medium and long term would be aroused. Currently, PPP should be placed under the framework of the medium and long-term fiscal planning, and the asset liability management of the accrual accounting system should be strengthened. Dong Zaiping (2016) deemed that the PPP would lead to government debt risk if misapplied, although it was regarded as a "sharp weapon" to alleviate fiscal pressure and govern government debt. The government debt of China's PPP penetrated through all aspects of the project, and manifested as direct and contingent, explicit and implicit. The governance and prevention of government debt in PPP mode needed to be carried out in a multipronged manner. Not only was it necessary to build an institutional system that ensured the continuous development of PPP and the debt risk management system throughout the full life cycle of PPP projects, and also to carry out classification budget and classification management on the government debt of PPP mode.

The current research on the essence and necessity of the PPP financial affordability evaluation is relatively few and not systematic enough, which are short of the analysis targeting on China's fiscal commitment risk management theories and the specific controlling framework, resulting in a consideration of fiscal affordability evaluation as a stumbling block to the development of China's PPP. Based on existing researches, this paper analyzed the necessity and significance of the existence of China's financial affordability evaluation. It also proposed suggestions of amelioration in the scientificity and reasonability of the evaluation methods through combining with the problems consisting in the methods and mechanisms of China's financial affordability evaluation.

\section{The Necessity of China's PPP on Financial Affordability Evaluation}

The potential promotion of efficiency and benefit serves as the main argument for supporting PPP. Good incentive mechanisms have motivated the power of private sector management and innovation, provided better value for money, and made up for higher private-sector borrowing costs and significantly increased transaction costs. Albeit PPP provides high-quality services at a lower cost, this mode has minus sides that may trigger fiscal risk. During the development of China's PPP, some problems have been exposed and a strict public budget control is required to restrain the free behavior of local governments.

\subsection{PPP Induces Fiscal Risk Easily}

First, public goods and services have their own particularities. PPP is used to provide public goods and 
services, whose service object is the general public. The service quality and efficiency concerns the governance efficiency and image of the government. Once the government departments begin to provide the service, they need to ensure a continuous operation of the service. Any interruption in the service will court public skepticism and dissatisfaction. This will inevitably lead to internal asymmetries between the public and private sectors, where the private sector will tend to take the initiative to strengthen its bargaining position, undertake less risks or ask for exorbitant prices. Moreover, once the project is launched, the government departments will be in a more passive position, while the private sector will even actively propose of renegotiation to seek higher profit during the process of cooperation, resulting in the project cost in exceed of the budget. When the government departments do not have a definite source of repayment, probably fiscal risk will be produced, and the impairment on credit and image will further deteriorate the situation.

Second, the construction and operation of infrastructure usually generate different types of risks, such as construction risk, demand risk, financial risk, political risk, force majeure and other risk. The core mechanism of PPP mode is to emphasize the risk transfer so as to achieve the purpose of a good control and incentives. Some risks, however, cannot be transferred to the private sector. Risk misallocation may lead to project failure and induce financial risk.

However, even if a good risk allocation agreement is reached, a complete circumvention for fiscal risk cannot be guaranteed, and it is also affected by the motivation and ability of both partners. Partial reason of the popularity of PPP is that it allows the government departments to enjoy the benefits of infrastructure in advance without payment in the current period. They can achieve additional supply of infrastructure without the requirement of borrowing immediately or increasing deficit. The fact that payment is lagged and does not affect the current budget may be the main reason of the adoption of PPP mode by government departments, rather than value for money. Therefore, although PPP can improve efficiency and solve the constraints of infrastructure investment, it is also an effective way to avoid fiscal expenditure restriction, delay government borrowing, conceal public investment expenditures in the short term, and remove debt out of the government balance sheet (Anderson et al., 2006; Funke et al., 2013).

Finally, PPP contracts are also affected by various uncertainties, including policies, economics, technology, etc. Public policy-makers are required not only to deal with the risks of individual projects, but also to control all kinds of risks and tackle with the budget allocation problem caused by PPP. Compared with the traditional government procurement, the PPP project needs to pass complex evaluation and procedures and involve the interests of multiple departments, causing that PPP projects have special difficulties in assessing expected costs, hidden financial risk and their impact. The uncertainty and long-term nature of PPP has weakened the motivation of the government to control fiscal risk in that it is very difficult to accurately predict fiscal revenues and expenditure in the coming decades. Potential speculative possibilities make the government who lack of responsibility and ability ignore long-term financial pressure, blindly launch projects beyond the scope of regional capabilities, and transfer most of the payment pressure and debts to the subsequent government, which can easily have the financial risk to conceal, accumulate and burst.

\subsection{Inexperience and Backward Legal System}

In China's Promotion Tournament Model which considers the economic growth in jurisdiction as the main goal, factors such as slow economic growth, declines in revenue and high debt strongly motivated local governments to use the PPP as a financing tool to break through budget and debt restrictions (Ji Fuxing, 2016). In the early stage of the large-scale and broad-range advancement of the PPP, the experience itself of public-private cooperation was not matured enough, the construction of legal system lagged behind the need of practice, and a mature legal policy system has not been set up yet. The level of supporting policies was relatively low, and a complexion of "two dragons regulating rivers and watercourse" presented where the provisions between the Ministry of Finance and the National Development and Reform Commission generated some contradictions, causing the practice department to be at loose ends and was not conducive to the development and risk control of PPP projects. In the process of rapid expansion of projects, the ideas of government departments lagged behind and the problems of lack in professional knowledge and operational experience were highlighted, resulting in a chaotic market order and deviation from the original intention of the PPP reform. The development of PPP acquires a maintenance of cautions and calmness attitude.

\subsection{PPP Projects Grow too Fast and Lack Financial Support}

Since that the central government has vigorously promoted the reform of PPP at the end of 2013, China's PPP has been advancing by leaps and bounds. From the view of the development speed and the investment scale, the status of "great leap forward" style has been demonstrated, where China has grown into the largest PPP market throughout the world within just four years and the demand has been continuously increasing. By the end of June in 2017, there were 13,554 projects admitted in total with an accumulated investment of 16.4 trillion yuan. The total amount of investment of projects involving government-pay and government-and-user-pay projects has reached to 11.3 trillion yuan, accounting for nearly $70 \%$ of the total project investment, of which, the government-pay project investment was 4.3 trillion yuan, accounting for $26.5 \%$ of the total project investment. ${ }^{1}$ The pressure, brought by the blow-out growth rate of PPP projects and huge investment scale, as

1 Ministry of Finance. The seventh quarterly report of the national PPP comprehensive information platform project library. 2017. 
well as the way of over-reliance on government subsidies, on local finances should not be underestimated.

In terms of areal distribution, regional concentration is relatively high, and local governments with weak financial resources are generally more willing to adopt the PPP mode. The number of warehoused projects in the western provinces and districts accounted for $53.6 \%$ of the total number, and the investment amount in the warehoused projects accounted for $49.9 \%$ of the total investment amount. ${ }^{2}$ In the western provinces such as Guizhou, Xinjiang, the Inner Mongolia Autonomous Region, Yunnan and Sichuan, both of the number of projects and the total amount of investment ranked among the top of the country.

On the one hand, it was an objective demand that the local governments actively adopted PPP to transform government functions and optimize public services provision under a fact where the western provinces had a backward economic development and large infrastructure gap, and PPP as an innovation for investment and financing mechanism can bring new vitality for them. On the other hand, the contradictions between fiscal revenue and expenditure in these areas were large, and PPP mode did not require a large amount of fiscal funds in the first few years. Thus, incumbent government was subjectively inclined to drive economic growth through PPP investment, improve public infrastructure in the jurisdictions, and turn the expenditure obligations over to next few governments, or hoped the central government to bear the ultimate responsibility, and maximum overdraft of future government financial capacity. As for who will pay for these projects, it is not their concern.

Under the current circumstances, the absolute scale of PPP projects or the share of the public investment expenditure should be limited. Only setting an upper limit on expenditure can ensure the certainty of fiscal funds. The implementation of the project can be determined by the amount of funding pool which is available for public sector projects, and limited by future available financial funds and the accumulative debts.

\section{Analysis of PPP Financial Expenditure in China}

The "financial affordability evaluation" defined by Guidelines refers to the identification and measurement of various fiscal expenditure obligations of the government and private sector cooperation projects, scientifically evaluating the impact of implementation of projects on the current and future fiscal expenditure." "Each year, the proportion of the expenditure obligations arranged from the budget by all PPP projects should not exceed $10 \%$ of the general public budget expenditure. The evaluation of financial capacity mainly includes three core parts: responsibility identification, expenditure measurement and capability identification. The conclusions of the evaluation are divided into pass and fail. For the "passed evaluation" project, the financial sectors at all levels will incorporate the fiscal expenditure obligations of these projects into the overall budgetary arrangement when they formulate the annual budget and mid-term fiscal plan, while they will not apply the PPP mode to the "failed evaluation" projects.

\subsection{Responsibility Identification}

The financial departments at all levels (or PPP Centers), as the main body of responsibility identification, it is supposed to qualitatively or quantitatively calculate the financial expenditure obligations of the whole life cycle of the PPP projects, including equity investment, operation subsidies, risk taking, supporting investment, and scientifically assess the impact of the project implementation on the current and future annual fiscal expenditure. Specifically, no matter what the payment mechanism a certain amount of financial funds are required to be paid. Therefore, the fiscal affordability of all projects must be evaluated (Table 1).

Table 1. PPP financial expenditure obligations.

\begin{tabular}{ll}
\hline \multirow{2}{*}{$\begin{array}{l}\text { In order to embody the government thought of cooperation, } \\
\text { investment } \\
\text { win-win and sharing, and enhance the consciousness of } \\
\text { supervision, the government should provide a certain capital } \\
\text { proportion of the equity expenditure when it forms a Special } \\
\text { Purpose Vehicle together with the private sector. }\end{array}$} \\
For the government-pay projects and the viability gap \\
funding (i.e. government-and-user-pay) projects, the \\
government pays the operating subsidy according to the \\
operation \\
subsidies \\
$\begin{array}{l}\text { performance evaluation requirement, the construction cost of } \\
\text { the projects is included in the operation subsidies. And for } \\
\text { most projects, the operation subsidies account for a large } \\
\text { proportion of total investment. } \\
\text { All projects have risk. In principle, private sector takes on } \\
\text { commercial risks such as project design risk, construction } \\
\text { risk, finance risk, operation risk, and maintenance risk, while } \\
\text { the government bears the risk of law, policy and minimum } \\
\text { demand. The risk such as force majeure are shared by the } \\
\text { government and private sector. Risk are contingent, that is, } \\
\text { the time of its occurrence and the loss incurred are all } \\
\text { uncertain. Thus, the risk taking expenditure must be preset } \\
\text { when evaluate the financial capacity. } \\
\text { Projects with different payment mechanism could involve the } \\
\text { government supporting investment. Land acquisition and } \\
\text { consolidation, project supporting, and the completion of the } \\
\text { connection between the project and existing related } \\
\text { infrastructure and utilities, and so on, all involve the } \\
\text { expenditure of the government financial funds. }\end{array}$ \\
\hline
\end{tabular}

In general, whatever the payment mechanism of PPP projects requires the government to invest a certain amount of financial resource. The government may also take on equity investment, risk expenditure, supporting investment and other expenditure, even if it is a user-pay project. Generally, the expenditure of each project has an impact on the expenditure of other projects, and the calculation of the project expenditures rely on each other, which means that each project is required to pass the continuous evaluation of

\footnotetext{
3 If the private sector separately establishes the SPV, the government will not assume the responsibility of equity investment expenditure.
} 
financial affordability.

\subsection{Expenditure Measurement and Capacity Evaluation}

According to the Guidelines, financial departments (or PPP centers) at all levels should consider comprehensively the characteristics, scenarios and occurrence probability of all kinds of expenditure obligations, and calculate the financial expenditure throughout the whole life cycle of the projects respectively. After the financial departments (or PPP Centers) has identified and measured the financial expenditure of each project, the financial affordability evaluation is carried out on the basis of summaries on all the PPP project expenditure obligations that have been implemented and planned to implement in a whole year. That is, whether the expenditure of the new project exceed the upper limit of expenditure should be examined based on the increase in expenditure, not only requiring an examination on whether the first payment of the new project will lead to an exceeded ratio out of the regulation, but also dynamically measuring their impact on fiscal sustainability from the annual total amount of financial expenditure during the duration of the contract.

\subsection{Substance of China's Financial Affordability Evaluation}

Financial sustainability has become the subject of the frequent discussion in most countries. In the 1920s, when it came to the issue of the public debt faced by France, Keynes (1923) mentioned that the French government needed to implement sustainable fiscal policies to meet its budget constraint. And he pointed out that when the national debt had reached an excessively high proportion of national income, the unsustainability of finance would be obvious. Buiter (1985) defined financial sustainability as the state of existence and capacity of a country's finance. When the country had the ability to pay off the debt, it showed that its finance is sustainable. According to the World Bank, the finance is sustainable if the fiscal policy does not require major adjustment to maintain sufficient solvency (for debt) at a given financing cost. ${ }^{4}$ The International Public-Sector Accounting Standards Board believes that the long-term financial sustainability depends not only on the ability of the financial resource to continue to provide public goods and services, but also on the solvency of the debt. ${ }^{5}$ Accordingly, financial sustainability is an evaluation of the current and future financial capability, which measures the ability of a government to provide public services and debt repayment and the financial risk they faced. When the government revenue is not sufficient to continue to provide public services and repay the debt, there is the issue of financial sustainability.

PPP has broken the monopoly of the infrastructure market

4 Deng Xiaolan, Huang Xianlin, Public debt, financial sustainability and economic growth, 2013 (4).

5 Ding Xin and Jing Xin, Research on the improvement of government financial report from the perspective of fiscal sustainability, Finace and Accountings, 2015 (16). and provided a new way for the supply of public services. However, more and more evidence indicates that PPP has brought fiscal risk, and the government needs to manage this risk actively. From the international experience, the financial risk can be mitigated through strong institutional rules or effective PPP evaluation and approval procedures. Some countries, especially those with stable and effective traditions in medium-term budgetary allocations, such as the United Kingdom, rely on informal long-term budget to control fiscal risk. While for some other countries with a weaker capability in budget control and insufficient state treasury, to prevent fiscal risk, they need to develop specific procedures of PPP with strict framework, such as limiting the budget expenditure committed by local governments, as a supplement to the existing debt ceiling, including the known government payment and possible contingent expenditure under the PPP contracts, ensuring the consistence between the upper limit of expenditure and the fiscal capacity in short, medium and long term, and controlling the impact of the PPP projects on macroeconomics and finance. In Brazil, the annual expenditure ceiling of PPP projects is $3 \%$ of the annual fiscal revenue, which is the standard applicable to all levels of government. The Republic of Salvatore stipulates that the present value of the quantifiable payment to companies and the possible future payment under PPP should not exceed $5 \%$ of GDP. Hungary stipulates that the nominal value of the new long-term expenditure commitments within a given budget year should not exceed $3 \%$ of the total national budget revenue. Peruvian PPP Law stipulates that the present value of certain debt and contingent liabilities of PPP projects cannot exceed 7\% of GDP. ${ }^{6}$ These restrictions may raise questions. Like, if the PPP is lower than the traditional procurement cost and achieves better value for money, why its expense should be restricted and independent from other public expenditure?

If the government could not make a prudent decision, and it is difficult to break through the backward budgetary mechanism and government accounting rule, the limit of total fiscal expenditure will at least ensure that the scale of the PPP projects will not grow too fast. Even in countries that are actively implementing PPP, the investment in PPP projects is no more than $15 \%$ of its total public investment. ${ }^{7}$ Through total control to limit the size of financial commitments and expenditure, government departments at all levels will be forced to strengthen communication among them, re-examine how to improve fiscal transparency and sustainability, and ensure that the expenditure ceiling covers the annual payment flows of PPP, and develop appropriate risk mitigation strategies. Governments implement PPP projects within the limited available financial resource, and control the possible payment risk and debt risk within an affordable range - it will not lead to fiscal crisis and seek for the best efficiency on this basis. From the perspective of risk prevention, the

6 K Funke, T Irwin, I Rial. Budgeting and Reporting for Public-Private Partnerships [C]. International Transport Forum Discussion Papers, 2013.

7 The International Affairs Unit of the Ministry of Finance, Asian Development Bank: Analysis of the financial effect of PPP project. China Finance, 2014 (9). 
essence of financial affordability evaluation is to ensure the sustainability of the finance, to better deal with the relationship between the PPP financial expenditure, the public service provision and its debt, and to avoid the local government blindly relying on the financing function of PPP which will intensity the imbalance between financial revenue and expenditure, in case of the occurrence of terrible fiscal situation.

\section{Deficiencies}

The evaluation of financial affordability of PPP project is an important guarantee for the government to fulfill the obligations of contract and to realize the sustainable development of public-private cooperation. However, there are still some deficiencies in the evaluation mechanism of financial affordability, which weakens its guidance.

\subsection{Low Credibility of Evaluation}

Firstly, in the administrative system of China, the financial departments at all levels as the main evaluation body in the administrative region of their level are more vulnerable to the pressure from higher authorities, having them loss their independence in the evaluation and making a discretionary choice for financial capacity evaluation, laying hidden financial risk and reducing the participation and confidence of private sector.

Secondly, when financial departments (or PPP Center) employ the consulting agency to assess the financial affordability through the way of government procurement, the evaluation made by the consulting agency may embody more of the wills of the financial sector, causing the evaluation of financial affordability to be formalistic, impeding the implementation of projects and decreasing the administrative efficiency of government.

Lastly, in practice, different consulting agencies may be selected through the government procurement methods, among which the adopted indicators of fiscal revenue growth rate, discount rate, and inflation rate are greatly varying. Even the same consulting agency may use different indicators in distinctive evaluation. However, PPP project requires large-amount investment, and thus, the adoption of inconsistent indicators will lead to the evaluation results in "large discrepancy due to a nuance", severely weakening the reliability of the financial affordability evaluation.

\subsection{Lack of Effective Management in Non-general Public Budget}

In the PPP projects, government departments may use land, real estate, equipment as equity investment or supporting investment. These physical asset investment is not contained in the expenditure obligations that need to be arranged from the general public budget, but these inputs still are the governmental assets. And the lack of supervision may lead to local governments over-investing with physical assets and inefficient allocation of state-owned assets.
In addition, the financial funds used in PPP projects can also be arranged from the budget of government-managed funds. For example, in the supporting investment of PPP projects, government compensation for land acquisition and demolition, land development expenditure, and urban construction expenditure belong to the expenditure items of state-owned land use right transfer revenue and the corresponding special debt income under government-managed funds budget; expenditure on the maintenance and construction of public facilities such as urban roads, bridges and culverts, public transportation, road lighting, water supply and drainage, gas and heat supply, and energy conservation management, as well as the expenditure for road cleaning, garbage removal and treatment, sewage treatment, and landscaping belong to the expenditure items used for urban public facilities and urban environmental sanitation under the supplement of urban public utilities, urban infrastructure supporting fees and corresponding special debt income. ${ }^{8}$ Local governments, beyond outside of general public budget, can use government-managed funds to pay for PPP projects under corresponding subjects. However, the evaluation of financial affordability does not address the use of government-managed funds budget.

The establishment of the budget of government-managed funds has specific pertinence. The background and purpose of the levy determine its earmarked characteristics and duration. Once the purpose of the funds collection is reached, it may face the reality of being merged or abolished (Feng Qiaobin, 2015; Deng Qiuyun 2016). The evolution of China's government-managed funds over years has vividly interpreted this feature. With the development of economy and society, and the enrichment of state financial resource, the funds items has decreased from 327 in 2000 to 23 in $2016 .{ }^{9}$ Whether the future specific revenue can meet the continuing payment obligations of PPP projects has not been fully demonstrated. This part of the expenditure drifts out of the $10 \%$ of the general public budget expenditure, neither subject to strict regulation and supervision, or possession of sustainability or affordability, and thus it has a certain degree of fiscal risk.

\subsection{Changes in Budget Adjustments May Lead to Excessive Bases}

According to the Guidelines, the amount of general public budget expenditure in the future can be calculated by referring to the average value of the relevant amounts and the average growth rate in the previous five years, when conducting financial expenditure capacity evaluation. And the growth rate can be adjusted according to the actual situations of economic development and the financial revenue. However, with the adjustment of the government budget, the general public budget revenue and the use of funds will be changed. The new Budget Act stipulates that

8 Ministry of Finance. Taxonomy of government revenue and expenditure in 2017. 9 Deng Qiuyun, Deng Liping, Budget for government-managed funds: Understanding based on Chinese characteristic finance, Finance research, 2016 (7) 
the "four budget" should remain intact and independent; the budget of the government-managed funds, the national state capital operations and the social insurance funds should be connected with the general public budget.

Government-managed funds budget and the national capital operations budget are transferred into the general public budgetary income, which has increased the scale of the general public budget revenue and expenditure. But the use of the transferred funds has been limited, and it cannot be uniformly arranged and used in the same way of other general public budget. ${ }^{10}$ With the advancement of reform, the use of government-managed funds budget will be limited in the future (Xiong Wei, 2012; Zhang Bin, 2015; Feng Qiaobin, 2015), or it will be fully incorporated into the general public budget (Zhang Wei, 2015), which can further expand the scale of general public budget expenditure. The expansion of the scale of general public budget expenditure resulting from the transfer or merger does not completely mean that the fiscal expenditure limit for the PPP projects can be expanded correspondingly. The current transferred funds still have the nature of special expenditure and cannot be put into the general public budget for overall use. Ignoring this problem may lead to government excessive commitments to fiscal expenditure beyond the affordability of the budget.

\subsection{The Cash Basis Cannot Meet the Requirements of Modern Financial Accounting}

Although Article 33 of the Guidelines points out that "the financial sector should, in accordance with the accrual accounting principles, perform the accounting record on government asset investment in PPP project and government-related projects assets, and reflect them in government financial statistics and government financial reports..." However, according to the investigation, it is found that, due to capacity and concept constraints, lack of incentive and punitive measures, the local governments do not record the assets and liabilities of PPP projects based on the accrual accounting rule, while they calculate the budget revenue and expenditure related to PPP projects just based on the cash basis accounting. However, the cash basis accounting does not require recording expenditure or debt in the early stage of the PPP project. It cannot comprehensively review the direct debt and contingent liabilities of PPP projects, which loosenes the overall control over the scale of the government's debt. It could easily lead to the underestimation of the long-term impact of PPP, and result in "fiscal illusion".

\section{Suggestions}

\subsection{Strengthening the Management and Supervision of Provincial-Level Financial Department}

The financial departments at all levels (or PPP Centers) or

10 Ministry of Finance: Notice on improving the budget system of the government, 2014. the consulting agencies hired by them lack certain independence in financial affordability evaluation, which makes the project evaluation lose objectivity. This problem can be effectively solved through assigning the whole provincial work of financial affordability evaluation to the provincial-level financial department (or PPP center). The provincial-level financial departments are familiar with the situation of economic development and financial revenue and expenditure in various regions of the provinces, and their administrative capabilities and efficiency are often more superior than those of lower-level financial departments. They are more able to grasp the macroeconomic situation and are less subject to administrative interference from the superior departments.

The financial departments at all levels could submit their value for money evaluation reports and specific financial information to the provincial-level financial departments level by level. The provincial-level financial departments (or PPP centers) shall, independently or with hiring a consulting agency, complete the financial affordability evaluation and disclosure the evaluation results to the public so as to prevent the evaluation from being formalistic, concretely facilitate the government to constantly examine the fiscal state, ensure its ability to perform the obligations and honor the financial commitments in full and on time. Uniformed evaluation by the provincial-level financial departments (or PPP centers) can also avoid the situation of the presence of inconsistent indicators, such as different fiscal expenditure growth rate, discount rate, inflation rate and other indicators in the same administrative region, thereby enhancing the scientificity and credibility of the evaluation.

\subsection{Standardize Government Expenditure}

When the government departments use physical or intangible assets as the equity or supporting investment, their expenditure are contained in the fiscal expenditure obligations borne by the government in PPP projects. The investment of PPP projects in physical or intangible assets means that these assets can no longer be reconfigured to other uses during the contract period and will lose the opportunity to create other benefits, resulting in an opportunity cost. Therefore, the use of these assets is equivalent to the fiscal funds, both of which represent the government expenditure in PPP projects, and only differ in the expression and liquidity. In order to improve the allocation efficiency of the local government assets, the monetary value of the physical or intangible assets should be evaluated according to the evaluation, and incorporate it into the expenditure limiting management.

At the same time, in order to better manage the expenditure of PPP financial funds, the financial affordability of government-managed funds currently used for PPP projects should be incorporated into the government-managed funds budget for the initiation of financial affordability evaluation, dynamic prediction on future revenue and expenditure in the light of corresponding subjects, and the evaluation on the affordability and 
sustainability of the government-managed funds budgetary expenditure. If the specific revenue of the annual government-managed funds budget fully used for PPP projects are greater than the special expenditure in each future year, then it pass the financial affordability evaluation, otherwise, it fails in the evaluation.

Besides, general public budgetary funds is transferred from the government-managed funds budget. Currently, only few of the transferred funds revenue can be used to PPP projects due to the limit on expenditure purpose. Therefore, it is necessary to explicitly stipulate on the budgetary funds pool used for the PPP projects by the local governments, specifically analyze the changes in the general public budget expenditure resulted from budget adjustments, and prevent cardinality from being too large to guarantee expenditure liability.

\subsection{Fully Establish an Accrual-Based Comprehensive Financial Reporting System by Government Departments}

The actual disclosure of PPP assets and liabilities is the foundation for the embodiment of the efficiency and value of PPP projects. The Chinese governments has attached too much importance to the capital flow information provided by the budgetary accounting, but neglected the record of the assets and liabilities, eventually causing an incomplete grasp of the government departments to the assets and liabilities. In order to avoid financial risk, the financial analysis should be improved to clearly reflect the actual state of government assets and liabilities, and clarify the medium and long-term financial impact of PPP.

The government accounting system should be changed in the short term, and the accrual accounting system should be adopted. The assets and liabilities of PPP projects will be explicit through coordinating with the reforms of medium and long-term budget framework and the government comprehensive financial reporting system, in case that the local government unilaterally pursuits economic development but ignores the coordinated and sustainable development of finance and economy. The fiscal data based on the accrual accounting system can accurately measure and reflect the deficits and debts of government, and improve the fiscal transparency so that the government can not only control the current debt scale and debt risk, and also facilitate long-term financial plan, improve the risk management of public-private cooperation, and ensure the sustainability of the medium and long-term financial plan and debt.

\subsection{Accelerating the Establishment of Medium and Long-Term Budget Mechanism}

Although there is a broad consensus on the need of PPP to be improved in project evaluation techniques to ensure that only the right projects are purchased, while a better project evaluation technique itself is not capable to ensure the financial affordability of the project. Given the disconnection between the projects and financial expenditure evaluation technique, the government may eventually purchase projects that are not within the budgetary capacity. It is necessary for PPP to place special attention to the budget because it would be easy to provide a way for the approval and initiation of projects without financial support if no proper control was adopted. The current medium-term fiscal plan only predicts the expenditure for the next two years after the annual budget, but the fiscal payment for PPP projects will continue for several decades. Therefore, the medium-term forecast is not sufficient to capture its impact, and long-term prediction is necessary.

Before an effective medium and long-term budget mechanism is established in China, the government should attempt to predict the inevitable financial expenditure, including debt payment and other potentially huge payment under long-term contracts, and gradually combine with the medium and long-term taxation and expenditure forecasting so as to gradually establish a sound medium and long-term budget system. It will be helpful for the financial sectors to understand the future financial situation which is a necessary extension to whether the government's spending commitments create financial risk.

\subsection{Accelerating the Legislative Process of PPP}

The uniformed policies and regulations, more of conflicts and contradictions and low effective level consist of the main reasons of the chaotic development of the PPP, and thus there is an urgent need of radical reform from a higher-level legal system. The legislation should clarify the function of various departments, rationalize the relations between the regulations and policies of various departments, and integrate the policies and regulations with better practical effects so as to resolve contradictions and conflicts. In the prevention of financial risk, it is particularly necessary to highlight the legal status and competent department of the financial affordability evaluation, so that the local government can maintain reasonable financial expenditure under the mechanism of financial capacity demonstration.

\section{Conclusions}

PPP provides better services at a lower cost. Especially under the cash basis accounting, PPP allows the government to obtain immediate investment while will not immediately cause a larger deficit, nor need to increase tax burden or cut off other expenditure. PPP benefits those government departments that are facing financial constraints and fearing the opposition of taxpayers or beneficiaries. Hence, some government departments may use PPP to meet their investment desire, even though they have realized that the cost of PPP may be higher than that of traditional procurement. Therefore, although people hope to enjoy the value for money brought by PPP, PPP cannot be used without restriction and its long-term impact should be controlled ahead of schedule. The evaluation of financial affordability is a good start for this goal. Setting an expenditure ceiling is still the best choice now before the problem of what expenditure proportion is reasonable and efficient has not 
been resolved.

At present, the evaluation mechanism of financial capacity is still not mature, which weakens its functions at standardizing PPP development, preventing financial risk and maintaining financial sustainability, and cannot fully guarantee the government ability of fulfillment on contract. To achieve the sustainable development of PPP and finance and economy, it is necessary to establish a sound evaluation mechanism, advance the government accounting reform, and comprehensively consider the influence of budgetary adjustments, especially accelerate the pace of legal construction.

\section{References}

[1] A Corbacho, G Schwartz. PPPs and Fiscal Risk: Should Governments Worry? Palgrave Macmillan UK, 2008.

[2] Budapest, Hungary, PPP and Fiscal Risk Experiences from Portugal, International Monetary Fund Working paper, 2006.

[3] Mona Hammami, Jean-Francois Ruhashyankiko, and Etienne B. Yehoue. Determinants of Public-Private Partnerships in Infrastructure. IMF Working Paper, 2006.

[4] BernardinAkitoby, Richard Hemming, Gerd Schwartz. Public Investment and Public-Private Partnerships. IMF Economic Issues, 2007.

[5] Y Jiang. Selection of PPP Projects in China Based on Government Guarantees and Fiscal Risk Control. International Journal of Financial Research, 2016, 8 (1): 99.

[6] R Shendy, H Martin, P Mousley. An Operational Framework for Managing Fiscal Commitmentss from Public-Private Partnerships. World Bank Publications, 2013.

[7] K Funke, T Irwin, I Rial. Budgeting and Reporting for Public-Private Partnerships. International Transport Forum Discussion Papers, 2013.

[8] Timothy Irwin. Controlling Spending Commitments in PPPs. Palgrave Macmillan UK, 2008.

[9] Rui S. Monteiro. PPPs and Fiscal Risk: Experience of Portugal. Palgrave Macmillan UK, 2008.
[10] Jia Knag. PPP Institutional Supply Innovation and Its Positive Effect. Economic Research Information, 2015 (5): 16-19.

[11] Wen Laicheng. Effective Control of the Financial Risk of PPP Mode. Accounting Research, 2014 (3): 1-1.

[12] Ji Fuxin. Research on Government Debt and Budget Mechanism of China's PPP Mode, Tax and Economics, 2015 (4): 6-11.

[13] Dong Zaiping. Analysis of Types and Characteristics of China's PPP Government Debt. Local Financial Research, 2016 (9).

[14] Wang Xi, Xia Qiang. Government and Social Capital Cooperation (PPP) Financial Commitments Management-Taking PPP project of Qingdao Subway X Line as an Example. Financial Research 2016 (9).

[15] Xie Lichao. Construction of Standardized PPP Management Mode to Boost Financial Reform. Financial Research 2015 (1).

[16] Wu Yanfang. Argument on Trustable Evaluation Mechanism of PPP Financial Capacity. Finance and Accounting Monthly 2017 (5).

[17] Bai Lupan and Wang Chuncheng. PPP and Local Public Financial Liabilities Management. China Finance, 2014 (14): 43-45.

[18] Huang Fangna and Wang Yue. The Impact of PPP Mode on Fiscal Sustainability. China's Collective Economy, 2016 (1): 86-87.

[19] Ji Fuxing. Study of China's PPP and Government Debt Issues. Financial Science, 2016 (1): 117-124.

[20] Feng Qiaobin. Research on Government Fund Management from the Perspective of State Governance, Local Fiscal Research, 2015 (7): 16-21.

[21] Zhang Bin. The Change of Government Fund. New Finance: Government Finance, 2015 (10).

[22] Xiong Wei. Earmarked Governmental Funds and Its Budgetary Properties. Jiaotong University Laws, 2012 (1): 62-73.

[23] Zhang Wei. The Governmental Funds Budget is No Longer Dedicated. Legal Daily, Sixth Edition, January 22, 2015. 